\title{
Urban and regional typologies in relation to self-sufficiency strategies
}

\author{
A. van Timmeren ${ }^{1,2} \&$ L. C. Röling ${ }^{1}$ \\ ${ }^{1}$ Climate Design \& Environment $(C D \& E)$, \\ Delft University of Technology (TUD), Faculty of Architecture, \\ The Netherlands \\ ${ }^{2}$ Atelier 2T, Haarlem, The Netherlands
}

\section{Abstract}

A topic of interest in sustainable urban planning and regeneration is the lack of integration of the 'essential' or 'critical flows' (water, energy, waste/wastewater).

In the Netherlands the shortage of space within urban planning leads to a rising demand for multiple use of ground and the intensification, or 'densification', of existing city districts and neighbourhoods. This process of densification can be considered positive for urban areas with lower densities, for it can improve the quality of the urban area and can improve the environmental efficiency of the public services. However, existing city-parts, invisible infrastructures and social structures are being aggravated due to this intensification. Furthermore, less public open spaces are to be included in future designs concerning these areas. This is also due to cut backs in maintenance costs and disposal of existing dispersed and fragmented parts of 'lost' monofunctional areas. In summary, one can say that the ecological and spatial conditions in and around cities are under pressure: transportation distances grow, protection and qualities diminish, and (infra)structures get more complex, less robust and less visible. There is however a possibility to revalue the liveability and ecological quality of open space in and around cities. The use of decentralized systems at district or local scale could introduce new urban functions to mono-functional and diminishing (green) areas and options for selfsufficiency.

This paper will focus on another background concerning urban planning based on 'Decentralized Concentration': The need for interconnection of essential urban infrastructures and 'red/green functions' based on another network philosophy and use, to achieve real (lasting) sustainable urban development. It focuses on network geometry and related backgrounds for design, integration and implementation of sustainable solutions concerning the essential flows at the scale of an urban district, a cluster of houses and individual houses.

Keywords: urban typology, self-sufficiency, decentralization, energy and sanitation. 


\section{Introduction}

The presented research tries to demonstrate the need to include interdisciplinary approaches to the integration of strategies for raising public awareness, marketing of the different qualities of water (cascading) and energy (exergy), and establishing a service business for building and operating more decentralised installations [1]. Within this framework integration strategies for wastewater management and sanitation, together with energy-generation, comprise direct linking with neighboring subjects like (urban) agriculture, health care and food security. The basis of this research forms an urban planning that is based on 'interconnection', as well as waste management in general and the organization, maintenance and assurance of indispensable parts of closed cycles. The research has been commissioned by the Delft University of Technology (TUD) as part of the CD\&E - Climate Design \& Environment - research to investigate and develop decentralised sanitation, energy and reuse technologies and their effects on urban planning, technical infrastructure and building lay-out. The aim is to research the spatial, social and environment related consequences of the implementation of decentralised smart technologies that are based on 'waste equals, food \& water', and to define the conditions within society to achieve a sustainable balance.

\section{The essential role of technical infrastructure}

\subsection{Interconnection and heteronomy versus decentralisation and autonomy}

With respect to both extremes, globalization (heteronomy by interconnection) and striving to complete (ecological) autarky cannot be seen as an optimal development for the so-called 'suprastructure', or, in other words, a good, democratic basis for societies. And what is more, neither of them (in their specific pure form) is to be considered a good basis for further, sustainable development of the structures for those societies. For the essential 'technical infrastructure' (i.e. energy, waste- and water infrastructure), the dynamics of non-simultaneous, slow transformation necessary for attuning the complex structures of society, the "flows" and nature (or natural processes) implies that it is wrong to still think in separate systems within integral development processes. That is, since there is an increasing interconnection and interdependence in the technical infrastructure of the essential flows. Although an increasing interdependence and heteronomy between people and their institutions can be noticed, de Vries and Goudsblom [2] claims that the dependence on natural forces has become less direct. The technical and social chains between the production of objects and their use ("source and service") are longer and more forked (complex). Two development processes concerning decentralized technology for the purpose of autonomy have come forward as topical: viz. first, the efficiency and improvements in the integration of sub techniques and coordinated, connected concepts, and, second, a better harmony between supply (input) and demand of the (different) sub flows. Additionally, there are two more 
general underlying development processes. The first is the environmenttechnical, environmental and, to some degree, also social optimization of decentralized systems within semi-autonomous projects.

In spite of the potential of the underlying optimization principle of the "scale economy" claimed in much of the literature and projects, and in spite of its importance, which was also proven, it has only been applied to a small extent. Consequently, there still are not many "economies of scale" in this area. However, the sub aspects concerning the application freedom and environmental integration (smaller sizes, fewer secondary demands, etc.) and user-related demands (comfort, ease of use, costs, etc.) do improve noticeably.

The second underlying development process concerns the link to economic applications related to the surroundings, often determined by soil or users, including taking nutrients back to agriculture and other lateral applications or possibilities, mostly concerning 'services' such as car-sharing systems. In addition to the possibility of other types of use of (agricultural) grounds, the link to agriculture (i.e. 'urban agriculture') may not only lead to a structurally different infrastructure (aboveground and underground), but also to different country planning as a whole, when applied on a larger scale. Some authors claim that this also implies a different (economic) organization: dependent on the scale of application, which amounts to incorporating decentralized participatory democracy or types of federation and confederation on different scale levels [1].

This also offers points of departure for interrelating "red" and "green" functions in environmental planning. Here, the aspects of vicinity and comfort are leading. In this situation, the search for an optimum scale of autarky or autonomy of the various essential sub flows in the built-up environment gains higher importance. The critical upper and/or lower limit set by the technology solving one of the sub flows will actually become indicative of the integrated system, and, consequently, of the other sub flows. However, it would be too easy to summarize the need for further-reaching sustainability and sustainable development, with autarky as their ultimate goal, with a plea for nature and natural processes in the city. The new structures should be found in larger freedoms, to be accomplished by closing circles on different levels than the ones belonging to current paradigms, so that a maximum variety of solutions become (or stay) possible.

In projects with a clear organization (or organizational structure) and with responsibilities clearly agreed on the often foreseen 'problem' of larger complexity often occurring in integrated systems is not necessarily perceived as only a disadvantage. For users and participants, it emphasizes the additional or 'lateral' fundamental needs of "identity", "participation", "relaxation", "freedom" and "self-expression". The critical limits that are set for parts of the integrated system, together with changing conditions regarding environment, use, technique or market, imply that such semi-autarkic systems should be considered unstable by definition. Because of the fundamental need of protection of maintenance, semi-autarkic projects should be able to meet such changes, either by means of a connection to a "backup" system (often on higher scale levels), or by means of parallel solutions (hence over dimensioning) within the 
system itself. In practice, we see far-reaching semi-autarkic projects being connected to central infrastructures. What still is unknown is that, to be able to connect to the electricity infrastructure, to a larger extent than approximately $30 \%$ of the network capacity, projects (subsystems) based on autonomy and/or renewable (discontinuous) sources new network philosophies (or network geometry) and use of these centralized grids should be introduced. Within the existing electricity network it is not possible to replace existing generation by generation through (variable) renewable sources for a larger extent than this $30 \%$. For the sanitation infrastructures alternative use of existing networks offers possibilities to cope with increasing costs due to aging and shortages on capacity due to expansion(s) and introduction of higher densities [1].

\subsection{Changed network philosophy as a basis for sustainable urban development}

The desired changed network philosophy described in the previous chapter has far-reaching consequences for the way in which these infrastructures are designed and integrated. Therefore it is important to realise that the stability or resilience of networks is directly related to the their complexity. It is not the components of the various structures that matter, but the way they are organized together as intelligent structures. It is important to learn from the organization structure and topology of other existing adaptive, complex structures. Recognizing the structures of each network is needed for combining their optimally ongoing development, possible decline and damage done to them, whether desired or not, with constant or increasing sustainability and certainty guarantees for user. Random networks with complex topologies often occur in nature, but also in culture. The complexity of many social, biological, communication and transport systems finds its basis in a network that is rather interrelated and that is defined by the system components and their mutual interactions. The mathematician Alexander [3] was one of the first to recognize the importance of the underlying structure as the basis for the possible notion of spatial planning and the accompanying physical and social networks. He distinguishes two scale-dependent opponent structures: the tree axiom and the semi-grid axiom. Later research [4] shows that even the smallest addition of random connections to a well-ordered network leads to advantages known from social networks [5], also known as the "small-world" principle [6].

As opposed to the social networks, the so-called "in-between distance" is relatively large. Within large-scale, aristocratic "small-world" networks, it turns out that a limited number of nodes have considerably more connections than the other nodes. These nodes are called "hubs" and can be considered as the pivots of a cluster. Well-ordered networks often consist of clusters, as do social networks. The importance of clustering is that the loss of one element will not result in any dramatic fragmentation of the network in disconnected subsystems $[7,8]$. The 'power law' implies that there is a fixed relationship between the total number of connections and the total number of nodes. This 'power law' is also known as "Pareto", "Zipf" or the principle of "self-organization", and may be considered as the main generic effect of the increasing networks or complex 
structures. Moreover, together with the principle of "self-repair" it is the main characteristic looked for in the possible application of "natural technology" for the facilities for the essential flows within sustainable urban development.

Two regimes can be distinguished in complex networks: an exponential regime, leading to homogeneous, egalitarian networks; and a "scale-free", aristocratic network, characterized by a clear difference in the number of connections per node. The aristocratic network structure approaches Alexander's semi-grid axiom, but has a structure more complicated and subtle, which make complex structures more easily to be included into the notion of the semi-grid. It turns out that the largest networks with known topological data in the aristocratic network structure show the same characteristics because of further-reaching interconnection (be it on world-scale or not): scale-free characteristics and a distribution of the transport connections according to the principle of the power law.

Almost all structures and networks designed or "ordered" may be put on a par with the tree axiom and have egalitarian characters. In addition to the urban development structures of most (newly) planned cities and city districts, the North American electricity grid is also a relevant example. The interdependence of communication networks that are relatively simply accessible and connected to or integrated into the essential infrastructures becomes larger and larger; they are almost always characterized by the aristocratic structure as described above. Because of the desired guarantees for operational safety and sustainability to users at lower scale levels, it is of importance to consider the effects of change (expansion, disturbance, breakdown) at higher scale levels.

Research into the resilience or safety of simplified networks, particularly distribution networks, shows that the aristocratic and egalitarian networks are very different from each other. When an uncoordinated breakdown occurs, e.g. because of incorrect use or age, egalitarian structures fall apart rather quickly whereas aristocratic structures allow for more than half of the nodes to be removed for the remaining parts of the network to perform well as a whole. When intentional breakdown occurs, e.g. in case of sabotage, the aristocratic structures turn out to be more sensitive, but it is relatively simple to secure the critical nodes in this type of network (in advance) or to isolate them (afterwards) without influencing the performance of the remaining network. The recent (2006) collapse (blackout) of extensive parts of the electricity grid throughout entire Europe after a relative small accident in Germany subscribes the previous, as does the Asian fall-out of Internet and other communication means after the December 2006 earthquake near Taiwan.

It can be argued that the best ultimate goal, when elaborating on the principles of the "economies of scale", is a complex, adaptive aristocratic structure of each of the networks, or perhaps of the whole that they form together (on regional, national or 'Euregional' and even global scale). It implies "scale invariance" and "self-organization", which are desirable aspects. A precondition is that the network grows continuously by new connections and (decentralized) clusters, and that new connections are connected to the network following the power law, with so-called "multi-connected" connections according to the principle of 
"preferential attachment". With respect to this, and in order to be able to understand the necessary process of clustering it is of importance to know the underlying "powers" of the principle of "preferential attachment", the principle of "the rich-get-richer". As to this principle, Bianconi and Barabási [9] argue that the aspect of "fitness" plays a role in competitive networks, or as they state: the principle of "fitter-get-richer". The aspect of "competitiveness" implies competition within networks rather than market competition between networks. The aspect of "fitness" should be defined differently for the various networks. For the essential flows and their infrastructures within urban development this implies a combination of the extent to which generation, collection and transport are flexible, uniform, consistent and technically \& spatially optimized. Supply guarantee together with sustainability is the key word, and this can be reached by tuning and adjustment of quality, optimizing rotation time and smart network design. If the connections between weak nodes are made stronger, by the simultaneous introduction of more "weak connections" between the important nodes in the system, the whole infrastructure can acquire more robustness and, eventually, more perseverance. This is when the necessary mutual connection between operability and sustainability is taken as a basis. This is where the importance of introduction of (more) decentralized sub networks comes in.

\subsection{Decentralization and autonomy as a basis for innovation and sustainability}

The application and fitting in of new decentralized techniques and/or alternative network structures, does not suffice for the accomplishment of "sustainable development". Too often there is tension between the mechanisms and the institutions that regulate motivation on behalf of individual or joint wishes. In following the conventional centralization paradigm, this type of "ritualism" stands in the way of a development into a society with more opportunities for changes according to the principle of "conformity" [10]. It creates niches of "sustainable development" of all alternatives that do not comply with the centralization paradigm. This occurs in the shape of concepts that can be placed under "rebellion" and even "separation". Examples are to be found in some of the Eco-villages, co-housing projects and Eco-districts, started by private sometimes collective - initiatives and in some instances as individual projects or silent-green examples, as e.g. Ruigoord, near Amsterdam (NL) [1]. Although projects such as the Eco-villages are to be considered as the application typology of "conformity" according to Merton's definition, they are often placed under the application typology of "rebellion" or even "retreatism" [10] by the dominant institutionalized authorities, looking at them from their own context on the basis of the current paradigm. Opportunities for a widely supported need for innovation are neglected here, and so is the chance of more significant "sustainable development", for example through scale invariance.

The problem of the directing centralization paradigm, which is even seen as imperative by some people, is often in the way of a more structural change. Nevertheless, the application typology of "rebellion", for example, which was started as a niche, can be taken as a method of allowing innovations to grow for 
the purpose of a more structural and large-scale use. In a way, Ruigoord is a spatial example of this, and the development of the Living Machine - at first in Eco-villages - is an example of a developed innovation based on natural processes. The starting points of the restructuring processes from the industry, known as "Empowerment" and "Business Process Re-engineering", are of interest for the (large-scale) systems and networks connected to the crucial flows that they may form the onset of research into scale invariance in the crucial infrastructures and their innovations. The "View Lean" is the basis for a structural redesign. This point of view takes a larger market-oriented attitude as its starting point on the one hand, and a more local or surroundings-oriented way of organizing on the other. The background for this is the global transformation of economies from being focused on "mass production" to a focus on "tailormade for the masses". Particularly inspired by liberalization processes, there is now almost only attention for the first aspect within the crucial flows and their infrastructures. The second aspect (surroundings-oriented attitude) implies a larger and a more structural change, and offers better opportunities for innovation and further-reaching sustainability (at several scale levels). It is the result of the increasing demand for user-specific, "on-site" solutions.

In current central infrastructures of energy as well as wastewater flows, the possibilities of an alternative network layout are not or not sufficiently taken into account. More and more connections are made between the various networks and sub networks in gas and electricity networks, but this occurs because of considerations of capacity and economic (business) perspectives, rather than on the basis of the principle of network geometry. Consequently, there is a direct interest for large-scale central networks to have subsystems as a decentralized cluster included into the complex network. Because of the principle of selforganization, it also offers the possibility and the guarantees for being able to make local decisions with respect to, for example, further-reaching sustainability without abandoning the principle of scale size ("economies of scale"). Systems within decentralized planning concepts may lead to networks, complex or not, with a more strongly decentralized network structure with part of the networks performing relatively autonomously. These may support flexible planning concepts in town and country planning. Moreover, the issue of a more precise attribution of costs to specific customers or transactions (which becomes more and more important as complexity decreases with ongoing liberalization) may be solved or may easier be solved [1].

\section{Consequences for urban planning and development}

\subsection{Design levels and location-specific characteristics as starting points}

It is of importance to distinguish design levels for tuning parties involved to the design and change processes. The direction into which decision-making and development become directive is of particularly importance. The social, geographical and/or political (decision) structures are decisive. They may vary strongly as regards their physical sizes. Moreover, many environmental effects 
are cross-border phenomena. With respect to the spatial demarcations, the fact that the "eco-device balance" may be taken in a literal sense to a larger or a smaller extent plays a part. The basis is whether or not external sources are used along with internal sources. There are also time scales at work: a specific amount of time has scale consequences (distance) for flows. This holds particularly for sanitation flows. Decreasing the rate of transport can restrict the spatial scale of a flow (and/or problem). This may however produce new problems in the restricted spatial area. In general, one could say that the specific location and the accompanying parties involved determine to what extent internal sources will be used only, or both internal and external sources will be used, and to what extent the solutions will be connected to the time scales. The location-specific characteristics can be divided into three groups: the characteristics that have been there originally and are typical for the site, or, in other words, the biotexture; the bio-climatic context; and the added layer consisting of the present or planned spatial typology. The bio-climatic context, or "genius loci", should be exploited optimally and is an important starting point in the in this research introduced "Programme of Possibilities" as a basis for sustainability in building and urban planning [1].

\subsection{Sustainable poly-centric development by decentralization and self-sufficiency}

The discussion about models for the spatial development of cities particularly deals with further-reaching global urbanization, including interconnection between networks concerning the different essential flows, especially energy related. In the various models, the focus is on how to deal with densities in relation to the various scale and design levels, and the relation with the "hinterland" and other cities or urban nodes. In the spatial models, density related aspects are roughly dealt with (high versus low density). It turns out that average densities of ecological (residential) districts are not higher than the average densities of development districts. On the contrary: the density in ecological settlements is even far under the average. In relation to "Type 1 state of sustainability" [11] (people live within the limits of natural, renewing ecosystems) in this research looked on as the most important aim for sustainable planning, three urban models are relevant: "the Compact City", "Decentralized Concentration" and the "Short cycles City".

Looked on from the efficiency of the infrastructure and systems, any type of density is all right, and can be realised and maintained sustainable. However, there is a paradox in the (centralized) density model of the "Compact City": further density produces advantages at a macro level (efficiency, restriction of use of space, restriction of mobility, reinforcement of social basis), but also disadvantages, including concentration of pollution, too few parks and gardens, less social than desired and more trouble and risks as results of increased ecological social basis. Of more current interest in (unidirectional) compression is the fact that the diffuse, further decentralized structures that resulted from usage are supported insufficiently. Apart from that, especially in the Dutch context (taken as a basis in this research), there are only few sites where the 
existing situation is successfully to be transformed into a structure based on the Compact City model, seen from an economic point of view. The countermovement "Light or Informal Urban Development" is no realistic alternative either. As an extreme kind of "urban sprawl" it takes up too much space and causes too much mobility and damage to the landscape. Some of the other characteristics, on the contrary, are quite easy to be used for the transformation of the "lost space" between cities or urban nodes, especially in cities where one or more qualities are under pressure, as is the case in nuisance zones. Examples are the (individual or collective) aspects related to management and ownership (privacy zoning, temporariness, involvement, freedom). Looked on from the viewpoint of "sustainable development" and self-sufficiency at lower scale levels, and seen in an environment-technical and social way, an urban culture can combine positive aspects of both types of spatial planning (the density of Compact City as well as the scattering of Light Urban Development or Urban Sprawl) following the model of 'Decentralized Concentration'. The decentralized concentration is based on the model of polycentric development and consists of several compact high-density settlements with centres that are situated at a certain distance of the main city centre. The accompanying design levels are different from the current ones (city, province, country). The scale or design levels that form the transition between collective and individual spaces, gain importance for the intermediate level of the ensemble of the neighbourhood and its involvement. The levels between city and province and between province and country - urban network and $(\mathrm{Eu})$ region - become of interest on account of the necessary interconnection, network geometry, and clustering, as explained before.

\section{Conclusion}

One could state that the infrastructure of the essential (or critical) flows, due to its 'path-dependent', long term character, importance of network geometry and the existence of a limited number of dominant actors per network or flow [1], is determinative to what degree a project - varying in scale from a (part of a) building to a city or region - will or can be sustainable. Especially the (waste)water infrastructure and the energy infrastructure can be characterised by transported flows which are not drawn up out of ongoing 'ecologisation' and dematerialisation but out of efficiency in central management and other economical factors. From the point of view of sustainability the technical infrastructure and with it urban development therefore seems to be insufficiently efficient. Science, and increasingly the market too, bring up a rising number of solutions that imply possible smaller scales of implementation. The considered benefits are a possible reduction of infrastructure and better visibility and tuning in to the demand and therefore more flexibility. However, there is no such thing as an optimal scale for implementation of decentralized-concepts, besides not every technology is suitable for any situation. Choosing a certain technology limits the available options further down the line. The need for a changed 
network geometry however makes the introduction of more decentralized sub systems (or clusters), possibly aiming at forms of semi-autonomy, necessary.

Spatial, (bio)climatical, but also social characteristics of a site have their influence on the most suitable technology. In theory a larger 'decentralized' system for a larger amount of users should be cheaper per capita. However, there seems to be a social limitation to the size. Also larger size limits the recycling of water flows because of increasing complexity. At the same time possibilities for energy cascading, or 'exergy', imply a possible larger scale than the building itself, but vicinity of different functions (i.e. different energy quality demands), possibly via higher densities. Meanwhile, the implementation of decentralized alternatives can improve the sustainable awareness of users: The layout and design of the system components can make organic waste- and water treatment as a part of the local water, carbon and nutrients cycles part of people's everyday experience. However, due to health regulations and overcautious authorities, the combination with other functions is still a relatively uncovered area. The 'EVA Lanxmeer' project in Culemborg in the Netherlands, based on a 'Sustainable Implant', together with the 'Vauban' and 'Flintenbreite' projects, both in Germany, give some directives for possible innovations concerning urban layout and planning consequences. Developments in related urban projects show that a symbiotic combination with public functions is possible. This would suggest that the scales of the neighbourhood or city district are appropriate scales of implementation (e.g. by integrating the system with other facilities). Waste and water treatment, combined with energy generation and nutrient recovery as a local enterprise (e.g. reusing nutrients in urban agriculture) than is another possibility that, combined with a larger system, could increase the over-all feasibility. It demands urban development following the model of 'Decentralized Concentration' with new forms of interconnection between agriculture and urbanization.

\section{References}

[1] Timmeren, A. van. Autonomie \& Heteronomie. Integratie en verduurzaming van essentiële stromen in de gebouwde omgeving. Delft University of Technology. Eburon Academical Publishers, Delft. 2006.

[2] Vries, B. de \& Goudsblom, J. Mappae Mundi. Humans and their Habitats in a Long-Term Socio-Ecological Perspective. Myths, Maps and Models', RIVM, Amsterdam University Press, Amsterdam. 2002.

[3] Alexander, Ch. The City is Not a Tree (1965). Architectural Forum, nr.04 \& 05 / Design, nr.02; translation in: SWB, Bergeijk, Belgium. 1966.

[4] Watts, D.J. \& Strogatz, S.H. Collective dynamics of small world networks. Nature vol.393, p.440-442. 1998.

[5] Granovetter, M. The strength of weak ties. American Journal of Sociology nr.78. 1973; and: Granovetter, M. The strength of weak ties: a network theory revisited, Sociology Theory nr. 1. 1983.

[6] Milgram, S. The small world problem. Psychology today nr. 1. 1967. 
[7] Barabási, A.L., Albert, R., Jeong, H. Mean-field theory for scale-free random networks. Online publ.: arXiv:cond-mat/990768 v1, Elsevier Preprint. 1999.

[8] Banavar, J.R., Maritan, A., Rinaldo, A. Size and form in efficient transportation networks. Nature vol.399. 1999.

[9] Bianconi, G., Barabási, A.L. Competition and multiscaling in evolving networks. Europhysics Letters, vol.54,no.4. 2001.

[10] Merton, R. Social Theory and Social Structure, Glencoe, Free Press, 1957. in: Röling, N. Gateway to the global garden. Beta/Gamma Science for Dealing with Ecological Rationality, University of Guelph, Canada. 2000.

[11] Frey, H.W. The search for a sustainable city. An account of current debate and research. Department of Architecture and Building Science, University of Strathclyde, Scotland, PLEA 2004, TUE, Eindhoven. 2004. 